\title{
Beyond 'Collaborative Economy' Discourse: Present, Past and Potential of Digital Intermediation Platforms
}

\author{
Jacob T. Matthews \\ Cemti / Paris 8 University
}

\begin{abstract}
Introduction
This paper draws on research looking into the hypothesis of a new stage in the historical process of cultural industrialisation - increased rationalisation, commodification and integration with external economic sectors - prompted by the expansion of digital intermediation devices (or dispositifs), ${ }^{1}$ in particular 'collaborative' web platforms and mobile applications (Bouquillion and Matthews 2010, 2012; Matthews 2014). The key proposal advanced in these works is that of a greater systemisation of the culture industries, ${ }^{2}$ simultaneously affecting both structural and ideological dimensions - the first pertaining to reconfigured ties between economic players and the relations of production and organisation of labour these industries rest upon; the second to the contributions they make to 'superficial' legitimisation of contemporary capitalism, and potentially to the effective redesigning of real processes of exploitation and domination.
\end{abstract}

How to cite this book chapter:

Matthews, J. T. 2017. Beyond 'Collaborative Economy' Discourse: Present, Past and Potential of Digital Intermediation Platforms. In: Graham, J. and Gandini, A. (eds.). Collaborative Production in the Creative Industries. Pp. 33-49. London: University of Westminster Press. DOI: https://doi.org/10.16997/book4.c. License: CC-BY-NC-ND 4.0 
While reinforced structural ties between so-called 'content' industries and communication industries (IT, electronic equipment and network players, telecommunications) developed to the advantage of the latter during the 1990s, the recent period has seen a simultaneous surge in the financialisation of culture industries and their increased articulation with consumer goods and service industries (Bouquillion, 2008, pp. 195-238, Hesmondhalgh 2013, pp. 185-99). The 'collaborative' web consolidates the culture and communication industries system, opening up a vast electronic marketplace (Bouquillion and Matthews, 2012, p. 8). Cultural 'content' appear to become mere consumer incentives, fully integrated into the capitalisation process of external sectors. This phenomenon has been interpreted as a 'culturisation of economy' (Lash and Lury, 2007), but as with the proposals of other 'digital optimists' (Hesmondhalgh, 2013 pp. 313-20), this thesis fails to take into account intensified rationalisation and commodification; in this respect, it would be more appropriate to speak of a further 'economicisation of culture'.

Considering the production of 'content', it has been noted that these evolutions are contributing to a polarisation between, on the one hand, premium offers (which still represent a direct source of capitalisation for major operators) and, on the other, so-called 'semi-pro', 'pro-am', or 'user-generated' goods, generally elaborated and distributed without any financial contribution from traditional industry players. Directly linked to this phenomenon is the growing significance of digital intermediation platforms. These last few contribute, of course, to the circulation of premium content ('legal' or otherwise), but their mode of capitalisation mainly proceeds from the direct or indirect exploitation of user production - whether in the shape of actual cultural or informational 'content', promotional elements such as prescriptions, or simply data. In any case, the key point is that these platforms allow for a significant transfer of costs towards user-consumers (Matthews and Vachet, 2014a, p. 36).

This brings us to the superstructural or ideological level of this systemisation. Indeed, the demand for increased participation of user-consumers within the capitalisation process cannot be without consequence with regard to the elaboration of culture in the anthropological sense, as theorised by Raymond Williams - i.e. culture as a set of symbolic and material productions, beliefs and practices, as a whole way of life (Williams, 2014 [1958], p.3). Side-stepping the enchanted discourse of empowerment and increased cultural diversity, my research questioned web and mobile application usage as vectors of ideological concentration, stressing nonetheless that such a tendency was perhaps not so much dependent on an inflation of intelligible representations, manifest ideological productions, but rather at work in 'the repetitive gestures of adhesion that the system requires of users' (Matthews, 2014, pp. 50-1). This hypothesis has been further explored with regard to what can be seen as an 'agglomeration of actions that individuals perform unreflectively to sustain the status quo', i.e. 'the banal repetition of the tasks that are assigned by the trusted networks, 
which seem to have little or no connection to the determination of political practices - opening one's laptop, logging onto a network, sending a phone message, etc.' (Gak and Karatzogianni, 2015, p. 137)

If the ideological construction of a new 'collaborative economy' around the web clearly contributes to the legitimisation of contemporary capitalism (Bouquillion and Matthews, 2010, pp. 51-76), I have since suggested that digital intermediation platforms might be considered as an 'avant-garde' of this new extended system of culture industries (Matthews, 2014, pp. 51-2). This implies that these dispositifs constitute models which can be applied to a variety of human activities. In enthusiastic accounts, the 'sharing economy' is based on a worldwide market, open to a multitude of player of all sizes, linked together by digital networks. The regular emergence of new markets and conversion of users into economic players gives this project an allure of realisation as long as one ignores the fact that a powerful oligopoly has emerged, and that even fringe players objectively dominate individual users. Moreover, we have shown that web platforms innovate mainly by reducing costs and allowing for an 'alteration of perceptions' that the various players have of the capitalisation process and the internal organisation of economic sectors (Matthews and Vachet, 2014b, p. 50). These elements point to significant cracks in the system, which are all the more apparent as the 'collaborative' web is still in many respects a socio-economic experimentation zone (Bouquillion and Matthews, 2010, p. 21).

The present chapter aims, firstly, to reassess two notions used in much of the aforementioned analyses and which continue to fuel significant interrogation and debate. The first is 'collaboration'. What objects and socio-economic processes does the notion of a 'collaborative' web refer to? What are its flaws? The second, frequently employed in both institutional/media discourse and in academic work, yet rarely defined, is the notion of intermediation platforms. How can this help describe and analyse socio-technical devices (dispositifs) having emerged over the past 15-20 years, as well as social constructs pertaining to earlier stages of capitalism? Secondly, I offer a contribution to deeper theoretical discussions about what 'collaborative' web platforms and mobile applications are doing to the culture industries in particular, but also to far broader areas of social and economic activity. This question cannot be seriously addressed without considering what relations of production these dispositifs command and what forms of labour they promote. It is one that we cannot shy away from, at a time when so many public discourses put forward the creative and democratic potentials of so-called 'social media' (Jenkins, 2006); the political and cultural promises attached to digital intermediation platforms oblige us to consider not only their infrastructural and superstructural 'attributes' (i.e. what they potentially change with regard to the production of economic value and cultural forms), but more fundamentally, the way they articulate these two realms. 


\section{The limits of the 'collaborative' web}

First of all, let us recall with Bernhard Rieder (2010) that in the notion of a 'collaborative' web, the second term refers to a particular technical structure:

In order to add a new functionality to the Internet all that is needed is to distribute to users the software that implements it; no infrastructural adjustment is required. On the web - which is also a software innovation this logic has been pushed to the extreme (...). New functionalities, activities and contents are offered each day and despite the conventions and tendencies that structure it, the space of possibilities is immense (Rieder, 2010, pp. 36-7).

This evocation points to the highly adhesive and extensive character of this 'web' - its ability to stick to a quasi-infinite number of human activities. In their characteristically euphoric style, Tim O'Reilly and John Battelle (2009) write: 'The web is no longer an industry unto itself - the web is now the world' (p. 12). Although this is clearly an attempt at self-realising prophecy, it is interesting to observe how their pamphlet Web Squared promotes a vision of socio-economic systemisation in which capitalisation opportunities would be exponentially multiplied. Their enthusiastic descriptions of quasi-universal, real-time, data management tools illustrate their affiliation with the wider discourse of ubiquitous computing (Pucheu, 2014).

As is well known, the 'web 2.0' label popularised by the same O'Reilly after the explosion of the dotcom bubble in the early 2000s was first and foremost a story-telling tactic designed to reassure investors who had been momentarily disorientated by the extent of speculative losses (Allen, 2007; Rieder, 2010). By identifying 'web 2.0' with the bubble survivors, the notion came to represent Internet-based economic activities which had placed their users at the heart of the value creation process (Bouquillion and Matthews, 2010, pp. 5-7). Despite its obvious ideological undertones, elements of this discourse remain relevant, for instance when these authors declare that 'the web as a whole is a marvel of crowdsourcing' (O'Reilly and Battelle, 2009, p. 2), explicitly acknowledging its imperious need of user-consumer 'participation'. If the web's potential to expand can seem unlimited, it's precisely because the notion associates the aforementioned technical characteristics with supposedly boundless reserves of capital and labour.

A second level where one encounters the question of the limits of the 'collaborative' web is that of the actual activities and sectors concerned. From a structural point of view, how far does the web stretch out, when 'the only true obstacle to the propagation of a new application is to be found in the meanders

of the attention economy' (Rieder, 2010, p. 37)? As a provisional answer to this key question, I suggest employing a broad definition, including all commercial and non-commercial entities whose activities are dependent on web interface 
and who integrate significant user contributions into their revenue model and/or mode of capitalisation. This definition implies that the 'collaborative' web is not restricted to niche and small- or medium-sized players, as we have previously suggested (Bouquillion and Matthews, 2010, pp. 17-26). Philippe Bouquillion has since pointed out that:

the collaborative web represents a new stage in the history of links between marketing industries and culture industries, as there is no opposition between the participative and cultural dimensions, on the one hand, and marketing, on the other, since the second - in particular the production of marketing data and targeted advertising - is 'fed' by the cultural exchanges of Internet users. (Bouquillion, 2013, p. 8).

If one follows this reasoning to its logical conclusion, it can be said that the 'collaborative' web does not replace any existing sectors (any more than it constitutes a new sub-sector in its own right). It simply integrates existing industries, enriching them both through its ability to articulate and intermediate, and by the 'collaborative imperative' that it propagates.

The semantic problem posed by this notion constitutes its third limit. At a primary level, the idea of collaboration implies a certain degree of reciprocity and recognition. Despite the negative connotation associated with the term in certain contexts, due to specific historical events (cooperation with the enemy), it is typically taken to refer to the freely consented participation to a common task. ${ }^{3}$ The hypothesis of collaborations between users, and $a$ fortiori between users and industrial players, can only be examined taking into account the relations of production that underlie these activities and dispositifs: who is collaborating with who, and how? (i.e. with what relations of subordination?) Previous research addressing these questions has focused on platforms supposedly designed for funding, producing and distributing cultural goods and services, in the absence of relations based on either waged or freelance labour. For instance, on video sharing or cultural crowdfunding platforms, how do the different types of usage allow industrial players to generate surplus value? Interesting insights have been provided by the analyses of 'immaterial' or 'digital labour'; critiques of the 'attention economy' have attempted to illustrate the importance of generalised and automated data production (Andrejevic, 2009; Comor, 2010; Fuchs, 2014; Hesmondhalgh, 2010; Peters and Bulut, 2011; Scholz, 2013; Terranova, 2000). My investigations into the management of user contributions or of intermediation processes which users take part in for example, in the isolated 'consumption' of music via YouTube (Matthews, 2014, pp. 49-50), or in the uploading of a project to Kickstarter (Matthews and Vachet, 2014b, pp. 44-7) - show that a significant part of the so-called 'collaboration' takes part without user-consumers being aware if it. That a minority deposits 'contents' knowing that the platform is legally entitled to use them to generate advertising revenue, and having thoroughly examined the site's terms 
of agreement, is one thing. But it is a wholly different matter when a majority of users access goods and services with the illusion of 'free' usage and without having the slightest understanding of the function they occupy within the complex threads of capitalisation spun with care by the owners and managers of web platforms.

Whatever their level of understanding of these last, 'collaborating' users are objectively in a position of subordination with regard to players who determine these capitalisation strategies, by virtue of their appropriation of the means of production and communication. In this respect, fully in line with the neoliberal-inspired evolutions of capitalism, the 'collaborative' web operates a cost transfer towards 'persons who do not have the capacity to propose or realise their own vision of the social order' (Schoenberger, 1997, p. 202). With the exception of consumer rights organisations, web users are bereft of representative institutions that might allow collective action and find themselves in a situation comparable to that of the least organised workers. In contemporary public debates, in France, the rare critiques of web players are centred around issues such as the 'right to be forgotten' or 'tax evasion'. Blablacar, Adopteunmec and others like Kisskissbankbank are almost unanimously applauded as French success stories, brilliant contributions to the 'collaborative economy', whilst the issue of property is never addressed (despite significant public financing of start-ups). This shows the prevalence of the 'creative industries' discourse, where protecting intellectual and industrial property rights is axiomatic.

In sum, it appears that the recurrent and positively connoted representations of 'collaboration' (and 'sharing') conceal specific processes of exploitation. I argue that these should not only be precisely analysed, but also countered, $a$ minima with the proposal of new social rights, based on the model of intervention powers acquired by workers' committees in various European countries, in the mid twentieth century.

\section{On the versatility of intermediation platforms}

The idea that intermediation platforms occupy a key function in the present evolution of culture industries has been discussed in a series of recent works. In their book, L'industrialisation des biens symboliques, Philippe Bouquillion, Bernard Miège and Pierre Mœglin (2013) draw up a critical synthesis of three key paradigms which are attempting to legitimise and encourage current industrial, cultural and social shifts. All three share this idea. Firstly, in what the authors name the 'convergence paradigm', the key players are 'those who develop a downstream command of sub-sectors via platforms integrating cultural and informational contents and services (...). These players are in charge of extracting and redistributing collected resources (Bouquillion, Miège and Moglin, 2013, p.40). Secondly, in the 'collaborative paradigm', the central players are those that 'occupy dominant - and even compulsory - meeting points 
for Internet users, contents and advertisers or other funders'. The authors add that this strategy is adopted by the most successful players of the web (ibid: 46-8). Thirdly, with the 'creative paradigm', intermediation platforms are again in a pivotal position due to their ability to articulate goods and service offers downstream, either by directly capitalising from these products, or to reinforce the capitalisation of external offers ( $i b i d: 56$ ). Although the origin of the surplus value extracted by these players is not explicated (a question we will come back to later in this chapter), it is clear that all three paradigms share an 'intuition' that these authors' more critical conclusions cannot dismiss: that of the growing importance of agents who 'interpose within sub-sectors and collect part of the generated value, to the detriment of creators, producers and not necessarily to the advantage of consumers' (ibid: 144).

In a recent publication Vincent Bullich and Thomas Guignard attempt to provide a clear definition of intermediation platforms and raise a significant question, suggesting that these might constitute a 'specific sector' in their own right. This proposition deserves further examination; for the while though, let us consider the five criteria identified by these authors. Firstly, intermediation platforms are described as 'distribution systems for goods and services that find their existence solely on networks' (Bullich and Guignard, 2011, p.2). Secondly, they carry out 'economic functions which are both informational (research and prescription tools) and transactional (securing transactions, logistic management, etc.)' (ibid: 3) Thirdly, referring to the works of economists Jean-Charles Rochet and Jean Tirole, platforms operate multi-sided markets, bringing together a variety of different players which are nonetheless interdependent for the exchange; doing so, they 'capture positive externalities produced by the interactions between the different sides, the setting up and management of the platform by no means being an aim per se.' (ibid: 5) Fourthly, the authors underline that although this model appears to be widely applied in sub-sectors linked to ICTs, it is not fundamentally innovative, either for the cultural sector or for other economic areas, such as finance and retail (ibid: 6). Lastly, they recall a decisive characteristic that Pierre Mœglin (2011) has already associated with these dispositifs: the value that these players (supposedly) add, and the profits they make, are not linked to an activity of 'content' production of their own.

Evidently the new web oligopoly players encompass these criteria (despite eg. Apple's historical core business of hardware and software production), sharing this key characteristic of being positioned 'above' production cycles, attempting to canalise transactions between diverse agents through their control over digital networks. But what is true for the 'big four' (Google, Amazon, Facebook, Apple) is also relevant to the strategies of thousands of web platforms struggling to poise themselves - in a blatantly parasitical manner - 'on top of' activities as varied as car-pooling, romantic relations, retail, accommodation, personal care, etc. (not to mention 'content' production). Their revenues are dependent on their ability to directly or indirectly 'monetise' cultural and informational flows. For these new intermediaries, surplus value extraction is not so much 
based on private appropriation of 'contents' via intellectual property rights and/ or sale of goods and services (although these streams do remain significant for some players). Digital intermediation platforms mainly rely on a model stemming from the fields of advertising and finance; 'commissions' are justified by their ability to link up individuals and/or groups with commercial entities, brands or investment opportunities. As Jeremy Vachet and I have pointed out, using the example of cultural crowdfunding and crowdsourcing sites (2014a), the platform constitutes a locus of transaction and translation - an instrument of ideological convergence. Presenting themselves as mere 'tools' which can be used in order to diversify cultural production, these platforms simultaneously engage with players of very diverse dimensions and rationales (from amateur to fully professional cultural producers, fans and individual funders, institutional funders, corporations, public institutions and agencies, charitable organisations, NGOs and so-called 'third sector' players). Intermediation is all about bringing these different agents to speak a common language.

Vincent Bullich and Thomas Guignard (2011) correctly point out that there is nothing profoundly novel in the model of digital intermediation platforms. An early study by Bernard Miège (1974), analysing the role played in the 1950s and 1960s by French 'comités d'entreprises' (CEs) in response to workers' demand for cultural goods and services, offers an historical example of what truly alternative intermediation platforms might look like. Although their existence is obviously prior to the advent of digital communication networks, three factors demonstrate this negative connection.

Firstly, Miège's study shows that - analogous to web players busy capturing the positive externalities produced by interactions between different sides CEs constituted, in a specific historical context, established 'meeting points' for a range of players. In this respect, one can speak of an intermediation platform linking together: workers (and their families) as cultural users/consumers; capital, i.e. the corporations contributing part of their revenues, and culture industry players; mutualist organisations (often linked to trade unions) operating leisure equipment, ticketing and cultural goods procurement services; and public and para-public institutions. Secondly, Miège's analysis of CEs show that they carried out clear socio-economic functions, of both informational and transactional nature - and unlike contemporary web-based players, the setting up and management of the platform did appear to constitute an end per $s e .{ }^{4}$ Thirdly, as with contemporary digital intermediation platforms, resources diverted to CEs may constitute a form of rent; but unlike web players, this is not based on the parasitical straddling of external production cycles or on the collecting and commercialisation of data or attention: the actual running of CEs was dependent on the voluntary work of employees and on a percentage of turnover deducted prior to the remuneration of both labour and capital.

These historical reminders are useful to question the supposedly ineluctable character of the socio-economic model which contemporary digital 
intermediation platforms rely on. Like Trebor Scholz's platform cooperativism, they suggest a potential for truly collaborative platforms and demonstrate the possibility of a viable and efficient alternative model (vulnerable precisely because of the obstacles it laid before capitalisation in this field and others). It is worthwhile envisaging what sets us apart from the era in which Bernard Miège conducted this study, but also persisting factors. One place to start is the author's conclusion that collective consumption of cultural goods and services was bound to increase significantly. A posteriori, this hypothesis is certainly one of the work's most surprising propositions, and appears to be in sharp contrast with the findings of much subsequent research pointing to increasingly individualised cultural practices. It is tempting to ask whether this individualisation has encountered its limits - or, perhaps, its logical outcome - with the advent of so-called 'social media'. In fact, one must acknowledge that cultural consumption has always had a collective dimension and implied a degree of productive activity on the part of supposed 'end-receivers'.

This observation is of course not new; it is central to the 'encoding/decoding' model of communication formulated by Stuart Hall in the mid-1970s (and developed in much subsequent research in the field of cultural studies). It is also a key element of the work of Brice Nixon, which re-examines the notion of audience labour and analyses the transformation of social communication into a process of capital circulation and accumulation (Nixon, 2013, 2014). Using a series of historical case-studies spanning from the emergence of the US publishing industry in the mid-nineteenth century to the advent of Google, Nixon attempts to demonstrate the continuity of a model where 'capital's ownership of the object of audience labour, culture, creates audience labour by creating a class relationship between those who own culture and those who do not' (Nixon, 2014, p.729). In order to illustrate this model, the author suggests an analogy with landed capitalism: in the same way that the landowner collects rent from the peasants who work his land, the culture industrialist owns the property of resources, and often tools, which allow user-consumers to produce cultural goods (or 'complete' their production): 'The copyright holder is a cultural "landlord" who does not accumulate capital through the sale of commodities by rather through the granting of access to a privately owned cultural resource in return for payment, i.e. through rent.' (Nixon, 2014, p. 731). ${ }^{5}$

These theoretical propositions allow us to reformulate the fundamental questions that this text seeks to address. Firstly, what material processes are representations of 'participatory' culture, or of 'collaborative' economy/society, attempting to account for? And how do digital intermediation platforms actually exploit so-called 'participative' or 'collaborative' usages? Secondly, can one consider that the production of culture is fundamentally modified by these phenomena - in the sense that the culture industries' modus operandi may be radically transformed? In other words, what do so-called 'collaborative' usages of web platforms do to the culture industries? 


\section{Back to the notions of capitalisation and cultural production}

Firstly, let us return to the question of shifts in relations of production within the culture industries - in particular to the broad segments that have been contaminated by the 'collaborative' web. The aim here is not to look at modifications in paid labour conditions: these are well documented, as well as the fact that these sub-sectors are characterised by the relative absence of waged labour (Baker and Hesmondhalgh, 2013; Deuze, 2007; McRobbie, 2015; Neff, 2005). The fact is that today, private appropriation of means of production and communication remains the dominant model (despite exceptions and the remnants of certain historical compromises). This evidently implies a class relation between user-consumers and owners of what Nixon names 'means of communicative production. Enchanted representations of collaboration can only endeavour to conceal, embellish or justify this objective material contradiction. As Christian Fuchs (2013) remarks, 'scholars who suggest that today's Internet is participatory advance an ideology that simply celebrates capitalism without taking into account how capitalist interests dominate and shape the Internet.' He adds: 'Web 2.0 is not a participatory system, and it would be better understood in terms of class, exploitation, and surplus value' (p. 215). The analysis of the exploitation of 'participative' usages by digital intermediation platforms implies an understanding of the capitalisation processes they allow, and in particular that stemming from the automated production of data, which has been perceived by many researchers as a central component of their 'business models. This leads us to question the hypothesis of renewed/modified relations of production deriving from 'positive externality capture' strategies (Bullich and Guignard, 2011, p. 5) bringing together numerous industrial players and userconsumers, without 'opposition between the participative and cultural dimensions, on the one hand, and marketing, on the other.' (Bouquillion, 2013, p. 8)

In the model proposed by Brice Nixon, communication and culture industries deploy three generic modes of capitalisation. Firstly, rents ensuing from the direct exploitation of cultural labour ('digital' or otherwise). Secondly, rents collected in exchange for the access to goods or services (cultural or otherwise), which entails direct exploitation of audience labour. Thirdly, interest from the leasing of 'fictive capital' to external players (advertisers, sponsors, etc.), which requires the indirect exploitation of audience labour. The first two cases imply a priori possession of intellectual property rights - although the author rightly points out that this is not the case with most web platforms, including Google (Nixon, 2013, pp. 233-6). Ancillary commercial activities, such as the sale of data produced by/on users, complete these three modes; however, although 'the data gathered through online surveillance can be, and often is, sold as its own commodity' it does not constitute the principal source of value (Nixon, 2013, p. 237). According to this thesis, capitalisation is based first and foremost on the exploitation of digital audience labour, and therefore on the control that web platforms are able to achieve of 'the means of audience communicative 
production' (Nixon, 2013, pp. 214-15). His analytic model nevertheless fails to specify whether automated data production is best considered as a mere optimising element for the interest that can be collected on the leasing of 'fictive capital' or as a form of payment 'in kind', by users, of the access rent, notably in the case of platforms providing 'free' services and products. Moreover, it is worth pointing out here that these three modes of capitalisation are being extended and applied in a variety of areas far beyond the recognised perimeter of the culture industries.

Secondly, let us observe how Nixon's propositions shed light on the hypothesis of a new stage in cultural industrialisation, induced by the proliferation of digital intermediation platforms. For this, it is useful to go back to some of the answers provided by the authors of Capitalisme et industries culturelles in the late 1970s, when faced with the key question: how does capital accumulate in the sphere of cultural production?

Cultural production (...) essentially consists of integrating artistic labour into a process of material reproduction. The specific characteristics of this articulation do not necessarily imply waged labour. On the contrary, submission of labour to capital rests upon the preservation of forms and frameworks of artistic labour which belong to pre-capitalist organisation: amateurism, free-lance labour, craft and cottage industry. These conditions allow the training and maintenance of the artistic workforce at a lower cost [and] limit the risks that capital faces due to the nature of use-values, leaving a significant part of those risks to those who create use-values, the artists; lastly, they provide capital with the most favourable means of making and distributing profits and potential rent. (Huet et al. 1978: 178)

I've reproduced several terms here in italic, as I wish to raise the following question, based on the model put forward by Brice Nixon: have these authors implicitly relied on a restrictive definition of 'artistic workforce'? In the same period, Nicholas Garnham (1979) set out to 'examine the specifically capitalist mode of media production (...), the ways in which capital uses the real process of media production in order to increase its value' (p. 139). David Hesmondhalgh (2013) points out that 'the cultural industries are concerned, fundamentally, with the management and selling of a particular kind of work' (p. 6) which he chooses to name 'symbolic creativity'. This author is careful to stress his differences with cultural studies perspectives such as those advanced by Paul Willis, who does indeed use the same term to praise the empowerment of cultural consumers (while refraining from analysis of the question of property of means of cultural production). When Paul Willis writes that 'symbolic creativity is essential to ensure the daily production and reproduction of human existence' (1990: 207) this can of course be read as yet another culturalist mantra. But if one relates this to Nixon's proposition suggesting that audience labour is an 
integrated component of the process which generates the use value that allows capital to reproduce, the formula takes on a wholly different meaning. One might then ask whether the authors of Capitalisme et industries culturelles were neglecting a crucial implication of their observation of the 'preservation of forms and frameworks of artistic labour which belong to pre-capitalist organisation' within what Garnham designated as 'the specifically capitalist mode of media production'. How might the amateurism that these authors refer to be intrinsically distinct from pre-industrial, authentically participative popular cultural forms? This interrogation concurs with the hypothesis that cultural products are not contained in commodified and industrially reproduced cultural 'contents'. From amateur dramatic production to the 'symbolic creativity' of game show audiences, to the contributions of web user-consumers, audience labour does appear to be one of the uncharted - or at least underestimated sources of capitalisation in culture and communication. This perspective offers a secure base to counter the assumptions of the 'collaborationist' discourses that Henry Jenkins promotes, which tell the story of a sudden resurgence of audiences from the ghettos of fandom in the 1970s. It also resonates with the conclusions of a study looking into consumer labour on crowdsourcing platforms which aptly remind us that the 'functional differentiation of society into two dichotomous spheres of "production" and "consumption" is an artefact of early industrial society.' (Kleemann, Voss and Rieder, 2008, p. 6) In this respect, we have now reached the end of a parenthesis during which cultural production and consumption were conceptually separated - including within the framework of political economy of communication.

Several observations must now be made. Firstly, if one must push aside the notion of a 'happily concluded' parenthesis (with 'participatory culture' atoning for the original sin of the culture industries), the hypothesis of a new stage of cultural industrialisation may however not be the most useful way of understanding what digital intermediation platforms are the name of. Let us go one step further and assume that if the category of audience labour was formerly the quasi-exclusivity of the culture industries, it is now effectively being extended to vast swathes of social activity via web platforms and mobile apps, in the same broad sweep that dissolves borders between professional and laymen, and transforms both amateurs and waged workers alike, into legions of freelance 'entrepreneurs'.

Nixon's analyses of Google are worth considering from this point of view, insofar as they firstly suggest a fundamental continuity with the culture industries:

While Google's users are relatively empowered as digital cultural laborers, as digital audience laborers they are no more empowered, or any less exploited, than any other audience laborers in other eras of the capitalist mode of communicative production. Even in the digital era, processes of communication are also processes of capital accumulation specifically because communicative capitalists control audience activities of 
cultural consumption and exploit audience laborers (either directly or indirectly). (Nixon, 2013, p. 237)

Here, the author refers to a distinction between, on the one hand, Google's strategy as an owner of platforms whose 'free' usage affords the generation of 'content' via the contributions of 'digital cultural labourers', and on the other hand, its more parasitical strategy, as a tool controlling access to 'content' that it does not own. Combined, these two strategies make for an apparent empowerment of user-consumers, while exploiting in fine digital audience labour to accumulate capital (Nixon, 2013, p. 249).

Secondly, Nixon's case study of Google illustrates three indicators of deep shifts which are being stimulated by intermediation platforms in the field of cultural production, and beyond. First he points out that this corporation has been able to amplify its impact as a 'communicative capitalist' by covering more and more aspects of digital communication, extending its control over an ever broader range of digital audience activities (ibid. p. 241). Google continues to create new devices for the exploitation of audience labour, not because it is forced to (as with numerous 'traditional' culture industries), 'but because these were relatively inexpensive ways for it to grow as a communicative capitalist' (ibid.). Finally, like other platforms, 'it produces none of the digital culture over which it assumes control, while that control is what enables it to extract surplus-value from the consumption of that digital culture, i.e. to exploit digital audience labor'. (ibid.p. 216)

Lastly, one cannot help wondering whether the proliferation of web platforms effectively marks the disappearance of the culture industries as we have 'understood' them for the past hundred odd years. What if this 'new stage in the historical process of cultural industrialisation' was in fact the end of these industries per se? And at the same time, what about the proliferation of discourses and (often extremely mundane, semi-automatic) practices which escort these new intermediation platforms in very diverse fields: are they to be 'understood' as a formidable expansion of ideological production far beyond the frontiers of the former culture industries?

\section{Conclusions}

The consecrated expressions of 'collaborative' web or 'social' media echo like an unconscious avowal of the intensification and diversification of user-consumer exploitation. Such expressions are poor attempts to conceal the contradictions of what I've earlier referred to as an extended system of culture and communication industries - which can hardly be envisaged as a sum of economic subsectors, but rests upon 'social engineering dispositifs' (Rieder, 2010) interfering in a previously unseen range of human activities and experiences. Platforms demand the 'collaboration' of user-consumers, yet doing so they reflect the key 
role that these last play in the production of both cultural and economic values, and in their capitalisation to the advantage of a minority of proprietors. Given the antagonisms that lie at the very core of this system, there are reasons to think that socialisation of means of cultural and communicative production, opening a pathway towards authentic forms of collaboration, can become a widely shared political aim.

Our task as critical intellectuals is to contribute to the emergence of concrete demands. For this, I suggest leaning on the gains of prior socio-economic and political struggles, such as the 'fixed forms of class struggle' (Miège. 1974, p. 269) that the CEs embodied in France between the 1950s and 1970s, and of which little is known by the younger generations that are so fiercely targeted by web platforms. The articulation between praxis and theory must not however be sacrificed in favour of the 'perversion of spontaneity' that Adorno rightly condemned in the late 1960s: 'The transition to a praxis without theory is motivated by the objective impotence of theory and exponentially increases that impotence through the isolation and fetishization of the subjective element of historical movement, spontaneity.' (Adorno 2005, p. 266) This is why I stress the importance of reassessing the question of mediations between relations of material production and cultural forms - that of the potential of autonomy, and inversely, of effectivity (Garnham 1979, p. 129) of cultural productions in regard to the dominant relations of production. The apparently low autonomy of 'collaborative' ideological production may be linked to the fact these cultural forms 'mime' their conversion into effective social forms.

'Collaborative' web platforms exist as real parasites on a fundamental material productive process, which their subsistence relies on in fine. But on a secondary level, their strength lies in their ability to coordinate and motivate labour, via 'collaborative' cultural forms - ideological discourse and practice and therefore to effectively contribute to the relative stability of relations of production. When Brice Nixon challenges us to radically extend the perimeter of what we have traditionally 'understood' as cultural labour, is he suggesting an underlying equation between the production of cultural forms (using resources and tools belonging to 'communicative capitalists') and the extraction of surplus value by the latter? Does this perspective point towards increasingly effective false collaborative cultural forms, which in turn may stimulate and/or consolidate shifts in relations of production that have decorously been called the 'uberisation' of economy? It would be foolish for theory to overlook this question.

\section{Notes}

1 This notion refers to the work of Michel Foucault, for whom the dispositif is fundamentally a socio-technical construct constituted by a set of internal, mobile parts, whose layout is precisely normative in the sense that it influences the environment, inducing certain social and ideological 
dispositions (Raffnsøe, 2008). Giorgio Agamben expands this definition to include 'that which, one way or another, has the ability to capture, guide, determine, control and ensure gestures, behaviour, opinions and discourses of living beings' (Agamben, 2007, p. 31).

2 The term 'culture industries' is used here in preference to that of 'creative industries' due to my contribution to previous works which deconstruct the latter, from the point of view of its heuristic viability and with regard to public policy implications (Bouquillion, Miège and Møglin, 2013; Matthews, 2015). However, this preference does not signify that the notion of creativity cannot be used within a critical analysis framework - as other chapters included in this volume fully illustrate.

${ }^{3}$ http://www.cnrtl.fr/lexicographie/collaboration, accessed 15/05/2015.

4 This point could be questioned if one considers the ideological function of CEs to have been a showcase for 'pre-socialist' satisfaction of cultural needs, in the same way that web platforms now contribute to legitimising a 'postpolitical' capitalism.

${ }^{5}$ Here it must be noted briefly that Nixon does not deny the validity of the 'traditional' cultural labour exploitation model theorised by political economists of communication since the 1970s.

\section{References}

Adorno, T. (2005). Critical Models, New York: Columbia University Press. Agamben, G. (2007). Qu'est-ce qu'un dispositif? Paris: Rivages.

Allen, M. (2007). Web 2.0: Discursive entrapment, empowerment or both? Vancouver: AOIR annual conference.

Andrejevic, M. (2009). Exploiting YouTube: Contradictions of user-generated labor. In P. Snickars and P. Vonderau (Eds.) The YouTube Reader, Stockholm: National Library of Sweden, pp. 406-24.

Baker, S. and Hesmondhalgh, D. (2013). Creative Labour: Media Work in Three Cultural Industries, London: Routledge.

Botsman, R., and Rogers, R. (2010). What's Mine Is Yours: The Rise of Collaborative Consumption. New York, NY: HarperBusiness.

Bouquillion, P. (2008). Les Industries de la Culture et de la Communication. Les Stratégies du Capitalisme, Grenoble: Pug.

- (2013). Socio-économie des Industries Culturelles et Pensée Critique: le Web Collaboratif au Prisme des Théories des Industries Culturelles, Les Enjeux de l'Information et de la Communication, 2013 supplement.

Bouquillion, P., Matthews, J. (2010). Le Web Collaboratif, Mutations des Industries de la Culture et de la Communication, Grenoble: Pug.

. (2012). Collaborative Web and the Cultural Industries System: a Critical Appraisal. Retrieved from http://www.observatoire-omic.org/fr/art/497/ collaborative-web-and-the-cultural-industries-system-a-critical-appraisal. html 
Bouquillion, P., Miège, B., Mœglin, P. (2013). L'Industrialisation des Biens Symboliques: les Industries Créatives en Regard des Industries Culturelles, Grenoble: Presses Universitaires de Grenoble.

Bullich, V. and Guignard, T. (2011). Les Plates-formes d'Accès aux Contenus : des Dispositifs au Cœur de la Reconfiguration des Filières Communicationnelles, Paper presented at the Médias 011 conference, Université AixMarseille 3, 8-9 December 2011.

Comor, E. (2010). Digital Prosumption and Alienation, Ephemera, 10(3/4): 439-54.

Deuze, M. (2007). Media Work, New York: Polity.

Fuchs, C. (2013). Class and exploitation on the internet. In T. Scholz (Ed.) Digital Labor: the Internet as Playground and Factory, London: Routledge, pp. 211-24.

Fuchs, C. (2014) Digital Labour and Karl Marx, London, Routledge.

Gak, M and Karatzogianni, A. (2015). Hack or be hacked: the quasi-totalitarianism of global trusted networks. New Formations, 84(84): 130-47.

Garnham, N. (1979). Contribution to a political economy of mass-communication. Media, Culture \& Society, 1(2): 123-46.

Hesmondhalgh, D. (2010). User-generated content, free labour and the cultural industries. Ephemera, 10(3/4): 267-84.

- (2013). The Cultural Industries, London: Sage.

Huet, A., Ion, J., Lefebvre, A., Miège, B., Peron, R. (1978). Capitalisme et Industries Culturelles. Grenoble: Pug.

Jenkins, H. (2006). Convergence Culture: Where Old and New Media Collide, New York: New York University Press.

Kleemann, F., Voss, G. and Rieder, K. (2008). Un(der) paid innovators: the commercial utilization of consumer work through crowdsourcing. Science, Technology \& Innovation Studies, 4(1): 5-26.

Lash, S. and Lury, C. (2007). Global Cultural Industry: The Mediation of Things, New York: Polity.

. (2015). Like a fraction of some bigger place - the "creative industries" in a peripheral zone: reflections from a case study, TripleC, 13(1): 144-62.

Matthews, J. (2014). Un Parcours de Recherche au Croisement de la Théorie Critique et des Approches Socio-économiques des Industries Culturelles. Bilan et Perspectives. Habilitation à Diriger des Recherches, Université Toulouse Jean Jaurès.

Matthews, J. and Vachet, J. (2014a). Le Crowdsourcing et le Crowdfunding Culturels dans le Web Collaboratif. In J. Matthews, V. Rouzé, J. Vachet, La Culture par les Foules? Le Crowdfunding et le Crowdsourcing en Questions, Paris: MKF Éditions, pp. 28-39.

(2014b). La Production et le Financement Collaboratifs : vers une Extension de l'Industrialisation Culturelle? In J. Matthews, V. Rouzé, J. Vachet, La Culture par les Foules? Le Crowdfunding et le Crowdsourcing en Questions, Paris: MKF Éditions, pp. 40-55. 
McRobbie, A. (2015). Be Creative: Making a Living in the New Culture Industries, Cambridge, Polity.

Miège, B. (1974). Les Comités d'Entreprises, les Loisirs et l'Action Culturelle, Paris: Cujas.

(1987). The logics at work in the new cultural industries. Media, Culture \& Society, 9(3): 273-89.

Mœglin, P. (2011). Vers une Redistribution des Cartes entre Opérateurs de Télécom, Fournisseurs de Contenus et Acteurs du Web? Paper presented at the THD Symposium, Université Paris 13, 28-9 April 2011.

Neff, G. (2005). The changing place of cultural production: The location of social networks in a digital media industry. The Annals of the American Academy of Political and Social Science, 597(1): 134-52.

Nixon, B. (2013). Communication as Capital and Audience Labor Exploitation in the Digital Era, Ph.D. thesis, University of Colorado.

Nixon, B. (2014). Toward a political economy of 'audience labour' in the digital era. Triple C, 12(2): 713-34.

O'Reilly, T. and Battelle, J.(2009). Web Squared: Web 2.0 Five Years on, Sebastopol, CA: O’Reilly Media.

Peters, M. and Bulut, E. (Eds.) (2011). Cognitive Capitalism, Education, and Digital Labor, New York: Peter Lang.

Pucheu, D (2014) Laltérité à l'épreuve de l'ubiquité informationnelle. Hermés, La Revue 68, 2014/1

Raffnsøe, S. (2008). Qu'est -ce qu'un dispositif? Symposium, 12(1): 44-66.

Rieder, B. (2010). De la Communauté à l'Écume: Quels Concepts de Sociabilité pour le 'Web Social'? Tic \&, Société, 4(1): 34-53.

Schoenberger, E. (1997). The Cultural Crisis of the Firm, Oxford: Blackwell.

Scholz, T. (ed.) (2013). Digital Labor: The Internet as Playground and Factory, New York: Routledge.

Smythe, D. (1977). Communications: Blindspot of western Marxism, Canadian Journal of Political and Social Theory, 1(3): 1-27.

Terranova, T. ([2000] 2013). Free Labor. In T. Scholz, Digital Labor: The Internet as Playground and Factory. New York: Routledge, pp. 33-57.

Williams, R. ([1958] 2014). Culture is Ordinary. In J. McGuigan (Ed.), Raymond Williams on Culture and Society, Essential Writings. London: Sage.

Willis, P. (1990). Common Culture: Symbolic Work at Play in the Everyday Cultures of the Young, Milton Keynes: Open University Press. 
